This is an open access article under the CC BY-NC-ND license Issue IV, 22 November 2021

\author{
Aigul Uteshkaliyeva \\ Candidate of Pedagogical Sciences, Acting Associate \\ Professor of Atyrau University named afterKh. \\ Dosmukhamedov \\ E-mail: aigul_bekbol@mail.ru \\ https://orcid.org/0000-0002-7571-6279
}

\author{
Galymova Nurzhamal Ruslanovna \\ Graduate student of Atyrau University named after Kh. \\ Dosmukhamedova 7M01301 "Management in \\ education" \\ E-mail: nurii-94@list.ru \\ https://orcid.org/0000-0002-4808-6910
}

\title{
Ways of organizing the educational process in elementary school based on the project-research form of educational activity
}

\begin{abstract}
This article examines the ways of organizing the educational process in primary school on the basis of the project-research form of educational activity. The relevance of this topic lies in the search and application of the design and research form of educational activity in primary school, where the main task of teachers is to quickly adapt to modern projects and the ongoing changes in updated learning. The XXI century is called the century of high or digital technologies. Creative, active, fastlearning and inquisitive people are in demand in any industry. The modern system of updated education develops children's research and cognitive structure of activity. Therefore, in the educational program, in almost every country, adjustments are made for the development of students' abilities, based on research and cognitive activity, where one of the first steps is primary school.

Keywords: primary education, project, design and research work.
\end{abstract}

Cite this article as: Uteshkaliyeva A.; Galymova N. (2021). Ways of organizing the educational process in elementary school based on the project-research form of educational activity. Challenges of Science. Issue IV, pp. 113-116. https://doi.org/10.31643/2021.18

\section{Introduction}

The reforms taking place in the education system in the Republic of Kazakhstan are the transition to a program of updated educational content. It was the impetus for the introduction of the updated content of education that was the activation of the learning function, the achievement of learning goals, through the organization of the educational process based on the project-research form of educational activity.

The initial stage of education contributes to the formation of the foundations of research and cognitive activity. According to the State Standard of the Republic of Kazakhstan, the goal of primary education is to create an educational space favorable for the harmonious formation and development of a student's personality with the basics of a wide range of skills:

$>$ Functional and creative application of knowledge

$>$ Critical thinking

$>$ Conducting research

$>$ Use of information and communication technologies

$>$ Application of various communication methods, including language skills

$>$ Ability to work in a group and individually [1].

\section{Main Research body}

The achievement of this goal is inextricably linked with the organization and construction of the educational process based on research and cognitive activity. The problem of including a younger student 
in educational and research activities turns out to be very relevant, but not always successfully solved. Because of this, it is necessary to actively search for favorable conditions for the organization of project and research activities of schoolchildren in the primary education system.

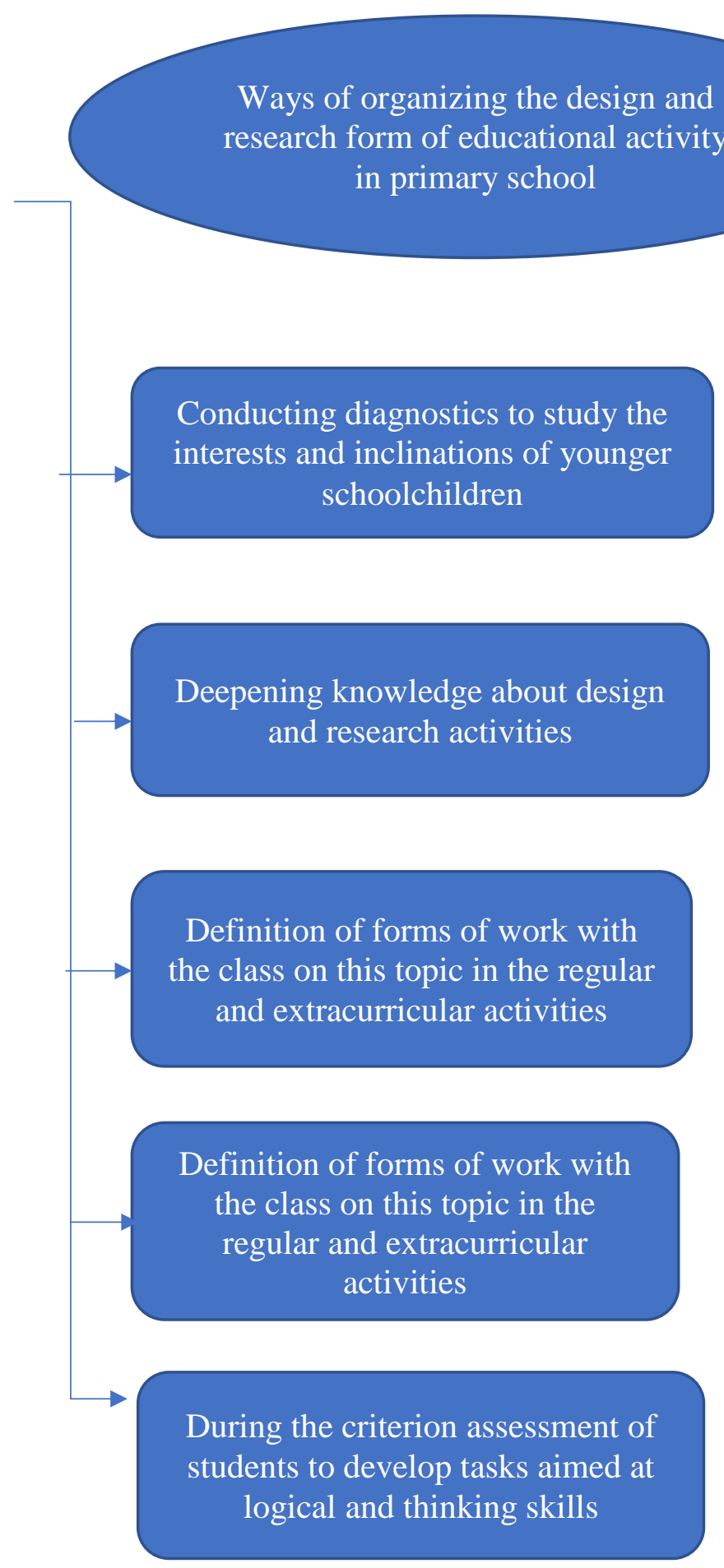

Figure 1 - Ways of organizing the design and research form of educational activity in primary school

An elementary school teacher in the organization of project and research activities is a carrier of knowledge and information, an organizer of activities, a consultant for solving a problem, obtaining the necessary knowledge and information from various sources, mastering a set of specific skills that will allow for the correct implementation of interaction with students in the process of project and research activities: 
$>$ the ability to find and set real educational and research tasks for students in a form understandable to children;

$>$ the ability to engage students personally with a valuable educational task;

$>$ ability to perform the function of coordinator and partner in the research search;

$>$ the ability to offer your help, not impose it;

$>$ the ability to be tolerant of students' mistakes and offer their help only when students begin to feel the hopelessness of their search $[2,3]$.

The purpose of design and research activities in primary school is to promote the involvement of younger students in an active cognitive process based on project activities for the formation of general academic competencies. In the course of the problem under study, we identified ways to organize the design and research form of educational activity in primary school (figure 1).

In the practice of primary school work, we focus on the most acceptable projects:

$>$ short-term projects are carried out both individually and in group form in extracurricular work or at home, information selection, presentation preparation, etc.;

$>$ mini-projects - conducted in the classroom and by the end of the lesson the finished result;

$>$ creative projects - involves the most free, unconventional approach in the performance of work (fairy tales, drawings, crafts, etc.) and the design of the results;

$>$ Research projects - substantiation of the relevance of the topic, the purpose and objectives of the study, mandatory hypotheses with subsequent verification and discussion of the results obtained.

When organizing the design and research form of educational activity in primary school, it is necessary to take into account the age-related psychological and physiological characteristics of students [4]. Thus, the topics of educational projects and educational research should be in the field of cognitive interests of the younger student and be in the zone of immediate development. It is advisable to limit the duration of the project or research at the level of primary general education to several weeks in the mode of scheduled extracurricular activities. In the process of working on the topic, you can conduct excursions, observation walks, social actions, work with various text sources of information, preparation of practically significant products, a wide public presentation with the invitation of students, parents, teachers and school administration.

When organizing project-research educational activities in primary school, it is necessary to take into account the use of methods and methods of activity in accordance with the class level $[5,6]$. So, in the 1st grade, the following methods and methods of activity are used in class activities: collective educational dialogue, examination of subjects, creation of problem situations, reading-examination, collective modeling; in extracurricular activities - games-classes, joint determination of his own interests with the child, individual drawing up of schemes, execution of models from various materials, excursions, exhibitions of children's works, which contributes to:

- maintaining the research activity of schoolchildren on the basis of existing ideas;

- development of skills to raise questions, make assumptions, observe, make subject models;

- formation of initial ideas about the researcher's activities.

In the 2 nd grade, the inclusion of younger schoolchildren in educational and research activities is carried out through the creation of a research situation through educational and research tasks and tasks and recognition of the value of joint experience and is focused on acquiring new ideas about the features of the researcher's activity, namely:

- to develop the skills to determine the topic of the study, analyze, compare, formulate conclusions, formalize the results of the study;

- to support the initiative, activity and independence of schoolchildren.

At this stage, the following methods and methods of activity are used: in scheduled activities educational discussion, observations according to the plan, stories of children and teachers, mini-studies; in extracurricular activities - excursions, individual compilation of models and schemes, mini-reports, roleplaying games, experiments.

On the basis of the accumulated research experience of schoolchildren, the third and fourth grades of primary school continue to further accumulate ideas about research activities, its means and methods, awareness of the logic of research and the development of research skills. In the process of learning, there is a complication of activities with an increase in the complexity of educational and research tasks, in the 
reorientation of the educational process to the formulation and solution of educational and research tasks by schoolchildren themselves, in the unfoldment and awareness of reasoning, generalizations and conclusions. Accordingly, the corresponding methods and methods of schoolchildren's activities are highlighted: mini-studies, research lessons, collective execution and protection of research papers, observation, questioning, experiment and others.

Thus, the enrichment of students' research experience based on individual achievements is ensured throughout primary school education. In addition to regular educational and research activities, it is necessary to actively use the possibilities of extracurricular forms of research organization. These can be various extracurricular activities in subjects, as well as home studies of schoolchildren. The results of the children's work must be presented and commented on by the teacher or by the children themselves (display, exhibition).

\section{Conclusion}

For the effective and correct organization of the design and research activities of younger schoolchildren, it is necessary to take into account the recommendations for a teacher at the level of primary general education:

$\checkmark$ strive to develop in each child his individual inclinations and abilities;

$\checkmark$ focus more on the process of research search during extracurricular activities;

$\checkmark$ teach children to identify connections between academic subjects, events and phenomena;

$\checkmark$ form a culture of intellectual work in children, the ability to extract information and knowledge, the ability to analyze, synthesize and classify the information they receive;

$\checkmark$ do not do for children what they can do on their own;

$\checkmark$ teach younger students to analyze learning situations and solve research problems.

Cite this article as: Uteshkaliyeva A.; Galymova N. (2021). Ways of organizing the educational process in elementary school based on the project-research form of educational activity. Challenges of Science. Issue IV, pp. 113-116. https://doi.org/10.31643/2021.18

\section{References}

1. The State compulsory standard of primary education dated July 27, 2007 "On Education" (SAPP of the Republic of Kazakhstan, 2012, No. 67, Article 958)

2. Slastenin V.A., Isaev I.F., Shiyanov E.N. Pedagogy. - M.: Publishing center "Academy", 2004. - 576 p.

3. Zimnaya I.A., Shashenkova E.A. Research work as a specific type of human activity. - Izhevsk, 2001.

4. Leontiev A.N. Activity. Conscience. Personality. - M.: Politizdat, 1987. - 304 p.

5. Uteshkaliyeva A.; Kinzhibayeva F. (2021). The main approaches to the organization of research activities in primary education in the Republic of Kazakhstan. Challenges of Science. Issue IV, 2021, pp. 95-98. https://doi.org/10.31643/2021.14

6. Suvorova S.L. Project and research activity of students: theory and practice // Scientific magazine "Kontsep, 2015 - p. 175 